\title{
El Re-entierro del Cacique José Gregorio Yancamil. Patrimonio, Política y Memoria de Piedra en la Pampa Argentina
}

Cacique's José Gregorio Yancamil reburial. Heritage, politics and memory of rock in the argentine pampas

Rafael Pedro Curtoni ${ }^{\mathrm{I}}$ y María Gabriela Chaparro ${ }^{2}$

\section{RESUMEN}

En este trabajo se discuten la idea de patrimonio, las politicas de reconocimiento indígena y las consecuencias de la construcción de monumentos como memoriales, considerando los aportes teóricos del denominado giro decolonial latinoamericano. Se presenta como caso de estudio la ceremonia de re-entierro de los restos mortales del cacique Rankülche José Gregorio Yancamil, realizada en el 2006 en la ciudad de Victorica, provincia de La Pampa, República Argentina. A través de la discusión planteamos que la concepción de patrimonio que ha predominado en las politicas de reconocimiento se vincula con las formas eurocéntricas de construcción del conocimiento y puede considerarse como parte de los efectos de la colonialidad del poder/saber. El mismo sentido de colonialidad es atribuido a la práctica de la arqueología como empresa científica moderna.

Palabras clave: Patrimonio, Colonialidad del poder, Giro decolonial, Yancamil, Monumento.

\section{Abstract}

In this paper we discuss the idea of heritage, the politics of indigenous recognition and the consequences of constructing monuments as memorials. As a frame of theoretical reference, we use the proposals developed by the Latin-American decolonial movement. We

CONICET, INCUAPA, Facultad de Ciencias Sociales, UNCPBA. Avda. Del Valle 5737 (7400), Olavarría, Buenos Aires, Argentina. E-mail: rcurtoni@soc.unicen.edu.ar

2 CONICET, INCUAPA, Facultad de Ciencias Sociales, UNCPBA. Avda. Del Valle 5737 (7400), Olavarría, Buenos Aires, Argentina. E-mail: chaparro@soc.unicen.edu.ar

Recibido: Marzo 2008. Aceptado: Junio 2008. 
present, as a case of study, the ceremony of reburial of the cacique Rankülche José Gregorio Yancamil, carried out in 2006 at the city of Victorica, La Pampa province, Argentina. Throughout the discussion it is argued that the predominant idea of heritage, commonly used in the politics of indigenous recognition, could be associated with the Eurocentric ways of constructing knowledge and also as part of the effects of the concept of coloniality of power. The same sense of coloniality it is attributed to archaeology as a modern scientific enterprise.

Key words: Heritage, Coloniality of power, Decolonial turn, Yancamil, Monument.

\section{InTroducción: Colonialidad y PATRimonio}

En ciencias sociales el reconocimiento del proceso de globalización implicó que los conceptos de "patrimonio cultural" y "manejo de los recursos", aplicados a lo arqueológico, sean considerados constructos occidentales y modernos. Esta reflexión, de carácter general y superficial, conlleva una crítica inmanente y un sentido de alerta a la imposición conceptual que suele caracterizar tanto al discurso como a la práctica académica. Como resultado, sobre todo a partir de finales de la década de 1980, se comenzó a cuestionar y a subvertir las implicaciones de las definiciones de patrimonio a la par de la puesta en escena de otras valoraciones asociadas a los mismos (Mamani Condori 1989, Merriman 1991, Preucel y Hodder 1996, Ucko 2001).

La pretendida aplicación universalista de esos conceptos (e.g. declaraciones de la UNESCO), y la transversalidad epistemológica, lingüística y de sentido de los mismos, constituyen expresiones no sólo de occidentalización sino más bien de relaciones de saber-poder. En el contexto sudamericano, la conformación de los Estados nacionales y la posterior concepción de la arqueología como empresa científica contribuyeron a la efectiva instauración y naturalización de esas relaciones. Como consecuencia de ello y expresado en su devenir histórico, el mundo académico fue entregando sus "mejores productos": la clasificación racial de la otredad, el establecimiento de jerarquías cronológicas para ordenar las diferencias (e.g. la otredad es localizada en otro tiempo-espacio "tradicional", "pre-moderno"), la cosificación del sujeto, el sostenimiento de oposiciones (e.g. naturaleza-cultura, sujeto-objeto, mente-cuerpo, etc.), la negación de la simultaneidad, la naturalización de 
relaciones sociales, entre otros (Castro Gómez 2003, Coronil 2003, Escobar 2005, Lander 2003, Mignolo 2003, Quijano 2003, Restrepo 2007, Verdesio 2005). De esta forma, planteamos que estos procesos, vinculados al "deber ser" de la arqueología y a lo "políticamente correcto", reflejan y son producto de nuestras relaciones con el pasado generadas bajo los efectos de la colonialidad del poder y la colonialidad del saber.

El concepto de "colonialidad" refiere a un patrón mundial de poder, articulado a partir de la conquista de América, que actúa por medio de la naturalización de las jerarquías raciales, codificando y legitimando las diferencias entre conquistadores y conquistados, lo cual permite dominación territorial y epistémica, explotación por el capital y subalternización de los conocimientos, experiencias y formas de vida de los dominados (Quijano 2003). La colonialidad del saber es vista como un dispositivo que organiza la totalidad del espacio y del tiempo de todas las culturas, pueblos y territorios del mundo, tanto del pasado como del presente, en un gran metarrelato universal en el cual la sociedad industrial liberal (sociedad moderna europea) es considerada la expresión más avanzada y culminante de todo el proceso. Asimismo, "las formas del conocimiento desarrolladas para la comprensión de esa sociedad se convierten en las únicas formas válidas, objetivas, universales del conocimiento" (Lander 2003: 23). Esta perspectiva del conocer, denominada 'eurocéntrica', concentró bajo su hegemonía el control de todas las formas de subjetividad, de cultura y de producción y reproducción de los saberes (Quijano 2003).

En Argentina, el pensador Arturo Jauretche reflexionó sobre la realidad del país en la década de 1950 en términos similares a los implicados en el concepto colonialidad del poder, considerando también las dimensiones geopolíticas y cronopolíticas del conocimiento. En su ensayo sobre la "colonización pedagógica" expresó que bajo la apariencia de valores universales se siguen introduciendo como tales "valores relativos correspondientes sólo a un momento histórico o lugar geográfico, cuya apariencia de universalidad surge exclusivamente del poder de expansión universal que les dan los centros donde nacen" (Jauretche [1957] 2004: 99). Asimismo, en la conformación de los proyectos nacionales las elites intelectuales o la "intelligentzia" según Jauretche, identificaron con "cultura" los valores universales consagrados por los centros de poder, excluyendo de esa manera todo lo preexistente. El ideal promovido por la "intelligentzia" consistía en crear Europa en América, por medio de la destrucción del indígena que podía ser un obstáculo, de la negación de todos los valores locales y de las posibilidades de creaciones originales. Así el proceso de "europeización que se 
practicó no consistió en la incorporación a la cultura preexistente de los valores europeos, sino en la derogación lisa y llana de aquella" (Jauretche [1957] 2004: 102). A ello se suman las narrativas hegemónicas que impusieron algunas formulaciones axiomáticas, construidas discursivamente, como la que sostiene la falta de continuidad entre el pasado prehispánico y los pueblos indígenas contemporáneos. Estas formulaciones pueden verse como resultantes de la colonialidad del poder/saber y a su vez forman parte de la esencia de la cosmovisión moderna y/o del modus operandi instaurado a partir del imaginario colonial.

En Sudamérica, las ciencias sociales en general y la arqueología en particular se conformaron en estos espacios de poder y no estuvieron exentas de las influencias ideológicas promovidas por el imaginario moderno/colonial (Castro Gómez 2003, Gnecco 2005, Haber 2004, Langebaek 2005, Politis y Pérez Gollán 2004, Verdesio 2005). A estos sentidos, se podrían agregar otros mecanismos de poder-saber que actuaron y actúan en la disciplina arqueológica y que pueden relacionarse con la efectiva instauración de la colonialidad del pasado/arqueología. Se puede sostener que la colonialidad de la arqueología se manifiesta tanto en una dimensión interna (en tanto práctica disciplinada de producción académica), como también en una dimensión externa (dado que constituye una formación discursiva "puesta en escena"). Por la primera, entendemos la promoción e imposición unívoca y universal, desde lugares de enunciación específicos (e.g. países centrales y anglófonos), de criterios de demarcación, acción y praxis, que se han expresado, básicamente, a través de la neutralidad valorativa, la preeminencia de la racionalidad, el principio de primacía del objeto, la escisión de problemáticas contemporáneas, la asepsia epistemológica, etc. Además, como disciplina, la arqueología pre-establece formas y prácticas institucionalizadas que configuran el "deber ser" académico y define relaciones de poder que implican la hegemonización de unas modalidades (paradigmáticas, teóricas) del conocer por sobre otras (Gnecco 2003, Restrepo 2007). En su relación externa la arqueología se expresa mediante formaciones discursivas puestas en escena como saberes "expertos" que no sólo conllevan la subalternización de los conocimientos "otros", sino que también al presentarse estructuradas bajo el formato científico desnudan sus propias construcciones, distinciones y categorizaciones, muchas de las cuales fueron naturalizadas y permanecieron incuestionadas (e.g. oposiciones binarias: hecho vs. valor; conocimiento vs. mito; material vs. espiritual, etc.).

Considerando el tema de este trabajo, algunos de los resultados específicos más destacados de los sentidos de colonialidad (relaciones de po- 
der-saber), se vinculan con la musealización y patrimonialización de ciertos aspectos del mundo indígena. A través de estos procesos, asociados por lo general con el reconocimiento y la reparación, pueden generarse ideas, imágenes y representaciones que suelen contribuir a sustentar la inexistencia actual del sujeto evocado (e.g. indígenas), en paralelo con una actitud de descrédito público y desaprensión ante los reclamos cotidianos efectuados por las mismas organizaciones originarias. En el caso aquí tratado, la construcción del monumento/mausoleo asociado al re-entierro del cacique Rankülche José Gregorio Yancamil, parece estar regida por una idea de patrimonio que busca escenificar y brindar una imagen "congelada" de "algo" de lo indígena. Sostenemos que el monumento, como "memoria de piedra", puede ser visto como efecto/producto de la colonialidad del poder, pues se vincula con una conceptualización de la idea patrimonial consonante con las formas occidentales, académicas y modernas de construcción, manejo y puesta en valor del saber. Bajo estas formas eurocéntricas de producción y reproducción del conocimiento se anulan, silencian y/o niegan, por medio de diferentes estrategias, las posibilidades de existencia de "otras" alternativas de construcción y circulación de los saberes.

Ante esta situación, la intención de este trabajo es discutir la construcción conceptual de la idea de patrimonio, las implicaciones de las políticas de reconocimiento indígena y los efectos de su monumentalización, a partir de un posicionamiento crítico enmarcado en el denominado "giro decolonial" latinoamericano (Castro Gómez 2003, Escobar 2005, Grosfoguel 2007, Lander 2003, Maldonado Torres 2007, Mignolo 2007, Santos 2006, Walsh 2007). Este marco de referencia introduce diversidad de cuestiones que impactan en la praxis como aquellas vinculadas con otras formas de construcción del conocimiento desde la diferencia y con las situaciones geopolíticas implicadas. Para esto se utiliza como punto de partida y ejemplo de aplicación la mencionada ceremonia de re-entierro de los restos del cacique Rankülche José Yancamil, realizada en la ciudad de Victorica, provincia de La Pampa, República Argentina.

\section{Discutiendo "PATrimonio"}

Desde que comenzaron a sonar a fines de la década de 1970, en los países angloparlantes, las primeras críticas hacia los fundamentos y consecuencias sociales de la arqueología procesual (Tilley 1989, Trigger 1981, 1984), no tardaron en repercutir en el área gestora de la misma, es decir en el Manejo de los Recursos Culturales (Shanks y Tilley 1987, Carman 
et al. 1995). La misma, para esos años estaba muy ligada a la arqueología de rescate ya que una de las ideas centrales era que los recursos culturales (o arqueológicos) "son limitados y no renovables". Por ese motivo, las críticas fueron de índole teórica y socavaron básicamente estos principios. En primer lugar, conceptualizar a los restos como "recursos" implica una mercantilización del pasado (Hewison 1987, Merriman 1991) y además, si aquello que consideramos cultura material es una construcción del presente y va cambiando témporo-espacialmente, ¿son los recursos culturales no renovables? (Ucko 2000, Holtorf 2001). Vinculado a esto se cuestiona la asignación de valores occidentales (científicos) que se otorga a los recursos y el desconocimiento de la existencia de diversas visiones o percepciones de otras culturas y de minorías étnicas (Ayala 2005, Bender 1998, Gnecco 2005, Layton 1989). Paralelamente se discute quién decide qué es patrimonio y qué proteger, como es el caso de Tiwanaku en Bolivia donde los aymaras fueron desposeídos de sus lugares sagrados (Mamani Condori 1989), y si hay una única forma de manejo de recursos culturales y de protección (Byrne 1991). Básicamente se cuestiona la intromisión del Estado y de los organismos internacionales en la definición sobre qué es patrimonio y en la gestión del mismo.

Indudablemente cuando hablamos de Manejo de Recursos Culturales se tiende a asociar al mismo con los organismos de cooperación internacional y las ONG. En este sentido, no se puede negar que la misma idea de "patrimonio mundial" y la creación de un movimiento internacional para la protección de sitios culturales y naturales que comenzó a gestarse en 1959, con la gran campańa de rescate del templo de Abu Simbel en Egipto-Sudán, son desde sus orígenes, una imposición de valores occidentales. Por un lado, el Comité del Patrimonio Mundial (World Heritage Committee) que pertenece a la Organización de las Naciones Unidas para la Educación, la Ciencia y la Cultura (UNESCO), y dependiente de las Organización de las Naciones Unidas (ONU), fueron creados como consecuencia de la posguerra e integrados, inicialmente, por Estados Miembros ubicados al oeste del Muro de Berlín. Asimismo, el Comité del Patrimonio Mundial (en adelante CPM) posee diversos organismos asesores integrados por expertos (principalmente arquitectos, juristas, conservadores, biólogos, museólogos, etc.), como el Consejo Internacional de Monumentos y Sitios (ICOMOS), la Unión Internacional para la Conservación de la Naturaleza y sus Recursos (UICN) y el Centro Internacional de Estudios de Conservación y Restauración de Bienes Culturales (ICCROM). Estos "expertos" fueron los encargados de la elaboración de la Convención sobre la Protección del Patrimonio Mundial Cultural y Natural de 1972, cuya misión es la 
de "identificar el patrimonio de valor universal excepcional en el mundo y garantizar su protección gracias a la cooperación internacional" (UNESCO 2000). Como puede observarse, los criterios de la ciencia occidental son los que priman, expresados a través de la evaluación de los expertos encargados de verificar si se cumple el principal requisito, el de "valor universal excepcional" o el tan discutido criterio de autenticidad (Ucko 2000). Hacia 1996, estos criterios se cristalizaron en una Lista del Patrimonio Mundial desbalanceada, entre otros cosas, porque en ella prevalecían los centros históricos (29\%), los monumentos y catedrales cristianas (20\%) y los palacios y castillos (6\%), ubicados en su mayoría en Europa (48\%), (Cleere 1996: 229). Sin embargo, hace más de diez años que esta situación se está revirtiendo. Desde el mismo seno de los organismos percibieron los desbalances y miradas eurocéntricas que predominaban en las valoraciones. Muchas veces, las opiniones de los expertos entraban en contradicción con los valores sagrados o espirituales de diferentes sitios. Asimismo en las Guías Operacionales, antes de 1996, se recomendaban formas de gestión y conservación que luego eran impuestas, desde los Estados, en detrimento del bienestar de las comunidades locales (Langford 1983, Pressouyre 1996, Wei y Aass 1989). Desde ese entonces, en las recomendaciones del CPM para la selección de sitios, cambiaron los criterios ajustándose a las nuevas discusiones teóricas y a los avances técnicos (Endere 2005, 2007).

Dos reuniones cuestionaron el rol del "experto", posicionado tan fuertemente en la Carta de Venecia (1964). Por un lado, ICOMOS Australia había revisado en 1988, algunos de los puntos de la Carta de Burra recomendando el reconocimiento de la significación de los lugares sagrados (Carta para la conservación de lugares de significación cultural, ICOMOS Australia 1979, revisada en 1988). Posteriormente se sumó la Carta para la Conservación de lugares del patrimonio cultural por ICOMOS, Nueva Zelandia (1993), donde se plantea que no alterar la asociación espiritual es más importante que preservar el aspecto físico de los lugares del patrimonio cultural indígena. Estos antecedentes permitieron que la Conferencia de Nara (Japón 1994) se centrara en la discusión acerca del valor de la autenticidad en la conservación y el manejo, concluyendo que "cada bien patrimonial se considere y juzgue dentro de los criterios del contexto cultural al que pertenecen", reconociendo que no es posible juzgar la autenticidad en base a un criterio fijo y que existen diversas formas de valoración en cada comunidad (Documento de Nara para la Autenticidad; Larsen 1995). 
En este sentido, actualmente, el CPM reconoce que el patrimonio primariamente pertenece a sus comunidades y alienta la participación de las mismas en la toma de decisiones, en la preservación y usufructo del mismo y hasta en la construcción de narrativas (Arizpe 2000, Avrami et al. 2000). Sin embargo, estos principios basados en la retórica multicultural, siguen reproduciendo relaciones de poder/saber eurocéntricas al promover la construcción conjunta de narrativas sobre la "otredad", pero sin considerar las propias historias de esos "otros" (Gnecco 2005, McNiven y Russell 2005, Santos, 2006). En otras palabras, el multiculturalismo, como parte de los paliativos posmodernos, promulga la inclusión de los "otros" por medio de diferentes vías como las políticas de integración (asimilación), síntesis y participación (por añadidura o simple sumatoria), que en sí mismas devienen estrategias que, por un lado, profundizan la falta de reconocimiento de la validez de otras formas de producción de conocimientos y por otro, ocultan y/o niegan la existencia de epistemes alternativas. Lo destacable, es que estos intentos pretendidamente superadores han sido generados y siguen generándose manteniendo una concepción disciplinaria estructurada bajo los principios y mandatos de los presupuestos epistemológicos y ontológicos de la ciencia moderna occidental. Los encargados del "saber experto" aparecen en esta retórica como los responsables fundacionales de la apertura académica y como los administradores absolutos de los conocimientos y de la "otredad". De esta manera, en la medida en que no se establezcan, más allá de lo discursivo, procesos decolonizadores (en principio) al nivel del sujeto y de sus prácticas académicas, no será posible superar las actuales exclusiones provocadas por las jerarquías epistémicas de la colonialidad global.

\section{Monumentos y Memoria}

Los patrimonios tangibles e intangibles son parte de las memorias que pueden servir como instrumentos de reconstrucción histórica de pueblos o grupos que quieren ser visualizados en contextos mayores. La memoria, configurada desde y por los cuerpos, los objetos, los paisajes y las prácticas (Piazzini 2006), puede considerarse como "la capacidad de conservar determinadas informaciones, remite ante todo a un complejo de funciones psíquicas, con el auxilio de las cuales el hombre está en condiciones de actualizar impresiones o informaciones pasadas, que él se imagina como pasadas" (Le Goff 1991: 131). Pueden identificarse al menos tres formas materiales de construcción de la memoria, como la arquitectura monumental, el culto a los patriotas y héroes y la demarcación de lugares históricos. 
La monumentalización de la memoria es una forma de documentar, construir o consolidar diferentes identidades (Achugar 2003, Jelin y Langland 2003, Castiblanco Roldán 2007). En este caso, a los monumentos habría que concebirlos como una herencia del desarrollo de la sociedad en un momento determinado. El monumento es un elemento que vincula pasado y futuro, existe como recuerdo de los que lo construyeron y de lo que ellos quisieron conmemorar y al mismo tiempo crea su propia historia.

Hacia fines del siglo XIX y durante las primeras décadas del siglo XX, en la República Argentina se comenzó con los procesos de construcción monumental, como pilares de la civilización y en sintonía con la memoria narrativa oficial, para recordar héroes, mártires y eventos. Es a partir de esos primeros ańos donde se transforma en una política de Estado y es aquí donde es relevante mencionar que el Presidente de la República durante los períodos 1880-1886 y 1898-1904, era el brigadier Julio A. Roca, quien había sido jefe de la denominada "Conquista del Desierto" (ofensiva armada contra los indígenas de Pampa y Patagonia realizada entre 1878 y 1885 , cuyo objetivo era obtener grandes extensiones de tierra por medio del exterminio y/o expulsión de sus habitantes). Esta "guerra contra el indio", como también se la llamaba, constituye uno de los principales etnocidios fundacionales del país (Bertoni 1992). De esta manera, en los actos oficiales donde se conmemoraban fechas patrias, se realizaban grandes desfiles militares para reafirmar y recordar las "gestas heroicas". A partir de 1887 y explícitamente a través de proyectos presidenciales se considera que es necesario consagrar en "fundaciones imperecederas las tradiciones honrosas de la patria [porque] quedan en la tierra apenas unos cuantos testigos de aquella edad heroica" (presidente Juárez Celman, citado en Bertoni, 1992: 98). A partir de ese momento, se constituye en normativa estatal la construcción de estatuas, placas, bustos y monumentos para glorificar e inmortalizar a los patriotas, no solamente en Capital Federal, sino también en cada plaza de la República Argentina.

En ese contexto, en la ciudad de Victorica (provincia de La Pampa), el emplazamiento de la denominada "Pirámide Héroes de Cochicó" en 1922 en la plaza central no constituye un hecho aislado, sino uno más dentro de un largo proceso que su comienzo, por lo menos en Argentina, podemos situarlo entre las décadas de 1880-1890. Durante ese período las elites gobernantes se vieron movilizadas ante el avance de millares de inmigrantes, especialmente italianos, que recreaban sus costumbres y festejos desde la nostalgia a su tierra (e.g. escuelas italianas) y reaccionaron ante la expresa amenaza extranjera que cuestionaba la hegemonía local. La 
construcción de una nacionalidad argentina fue la salida que incluiría la gran diversidad interna y las constantes transformaciones que se sufrían. A partir de lo cual se implementaron una serie de estrategias "de acción, comunicación y control para la encarnación de la nacionalidad, respaldada en la tradición patria" (Bertoni 1992: 79-80). En esta política estatal, la escuela y la enseñanza de la historia con la celebración de las fiestas patrias fueron instrumentos claves para su puesta en funcionamiento, así como también los museos. En este sentido, esos aspectos de la memoria política de la nación se convirtieron en elementos cohesionadores del ciudadano. Estas consideraciones remarcan que la construcción de monumentos como memoriales nacionales ha sido una preocupación sostenida por parte del Estado, frecuentemente vinculadas con narrativas políticas e ideológicas que determinan qué, cómo y dónde conmemorar (Achugar 2003, Jelin y Langland 2003).

Casi un siglo después y en la misma plaza central de Victorica se erige otro monumento (mausoleo), para depositar los restos del cacique José Yancamil, el cual intenta recrear la memoria colectiva de un pasado no muy lejano que la historia se encargó de invisibilizar mediante hechos, la construcción de textos y discursos oficiales. Como trataremos de analizar, parece ser que el Estado, tanto en el pasado como en la actualidad, es el que decide qué, cómo y en qué contextos se debe recordar, adoptando criterios y fundamentos del saber "experto".

\section{“El Patrimonio cultural” Rankülche}

En los últimos años se han efectuado, en la provincia de La Pampa, diferentes acciones de homenaje, restitución y "reparación" vinculadas al mundo indígena de los Rankülche. De manera concisa mencionamos los casos más relevantes que se han desarrollado. En 1985 la Laguna de Leubucó, asentamiento del cacique Panghitruz Güor durante el siglo XIX, fue declarada "Sitio Histórico Provincial" por la Subsecretaría de Cultura de la provincia. En 1992 se construyó el primer monumento para representar el encuentro entre el cacique Panghitruz Güor (conocido también como Mariano Rosas) y el Coronel Lucio V. Mansilla, acaecido en 1870 con motivo de discutir tratados de paz. En 1994 y como parte de los homenajes y reconocimientos del lugar, se construyó un "Monumento a Leubucó" de forma piramidal y dos metros de alto, sobre el cual se colocaron dos tacuaras cruzadas. En 1999 otro gran "Monumento a los Rankülches" fue inaugurado en el mismo sitio. Este consiste en una estatua de estructura hueca 
laminada con placas de metal e incisiones de bronce de 8 metros de altura y denominado localmente como "robocop" (Curtoni 2004, Endere y Curtoni 2006, Lazzari 2007). Finalmente, en 2001 se concretó la restitución de los restos del cacique Mariano Rosas (Panghitruz Güor) por parte del Museo de Ciencias Naturales de la ciudad de La Plata. Los restos del cacique fueron trasladados hasta la ciudad de Victorica y de allí a la Laguna de Leubucó para ser depositados en un mausoleo construido para tal fin. En el mismo lugar la comunidad Rankülche erigió un rehue y un área con enramada y quincho destinada a la realización de ceremonias (Endere 2002, Endere y Curtoni, 2006).

En la mayor parte de los casos mencionados, las autoridades provinciales han tenido una activa participación y poder de decisión sobre los contenidos de las políticas de reconocimiento. De esa forma, parece ser que en la provincia de La Pampa "el Estado administra la etnicidad" (Mendoza 2007: 139), reproduciendo acepciones sobre la idea de patrimonio consustanciadas con las representaciones académicas de la modernidad occidental, en las cuales primaba un sentido universal, objetivo, estático y esencialista de las mismas. Lo contrario ha ocurrido con los actores de las comunidades originarias, quienes han tenido menor participación en las decisiones plenas y relativas a los planes de manejo del "patrimonio" cultural indígena (Endere y Curtoni 2007, Lazzari, 2007). Así lo expresa el lonko (jefe) de la comunidad Rankülche Germán Canuhé: "La provincia inició un proyecto de restitución de varios caciques y su intención era construir tres monumentos, uno al inmigrante, otro al indio y otro al criollo. En esa época no se nos consultaba. Al indígena en La Pampa no se le daba entidad, entonces al no darnos entidad, ellos hacían las cosas como querían" (Canuhé, com. pers. [entrevista personal] 2005).

Anteriormente habíamos señalado el carácter tradicional y colonial del concepto de patrimonio que parece sostener, poner en práctica y reproducir el aparato estatal de la provincia. Asimismo, otra faceta interesante de discusión es la connotación de singularidad invocada con la palabra patrimonio, implicando la idea de algo compacto, monolítico, homogéneo, siendo en consecuencia, incontroversial, coherente y consensuado. La idea de un patrimonio pareciera anular la existencia no sólo de otras miradas sobre el mismo fenómeno, sino también la posibilidad de puesta en escena de otras expresiones que podrían ser designadas con aquel concepto. Esta forma de concebir al patrimonio se vincula con un contexto de poder más amplio de producción, reproducción y manejo de los saberes, donde no sólo se construyen visiones hegemónicas, únicas y universalizantes, sino también se nie- 
gan o desacreditan otras, considerándolas frecuentemente como leyendas, mitos y/o relatos pseudocientíficos. Estas caracterizaciones y clasificaciones conforman parte de las estrategias y efectos de la colonialidad del pasado/ arqueología donde también se prescribe la dependencia en la materialidad certera como condición indispensable de legitimación discursiva. Quizás esta prescripción se vincule con la irreductible necesidad de la modernidad/ colonialidad occidental y de la empresa científica de hacer tangible e indudable aquello considerado como patrimonio.

En este caso, podríamos argumentar que en la ceremonia de re-entierro de Yancamil esa necesidad se expresó en los elementos considerados como más importantes de la perfomance: por un lado el cacique, pero a través de sus "restos", y por otro el "monumento/mausoleo" realizado con un bloque de mármol crudo como referencia del personaje. En estos dos referentes, "restos" y "monumento", pero sobre todo a partir de este último, dado el carácter invisible y oculto del primero, se pone en juego la potencial activación y construcción de memoria promovida por el acto de reconocimiento y reparación.

\section{"Memoria de piedra": el re-entierro de Yancamil}

El 19 de agosto de 2006 en la ciudad de Victorica, provincia de La Pampa, se realizó la ceremonia de re-entierro del cacique Rankülche José Gregorio Yancamil (Figura 1). La organización de las actividades estuvo a cargo de representantes de la comunidad indígena local y del gobierno provincial y municipal. Los restos mortales de este jefe indígena se encontraban en una tumba del cementerio municipal de Victorica, allí fueron exhumados el día 18 a la mañana y trasladados en procesión hasta un salón de la Municipalidad ubicada frente a la plaza central. En la Municipalidad se rindieron honores al cacique durante todo el día con guardia permanente y visitas de distintos representantes provinciales y nacionales. A la mañana siguiente los restos fueron depositados en un monumento/mausoleo de forma cuadrangular construido con un bloque de mármol crudo colocado sobre un lateral de la plaza (Figura 2). Los restos de Yancamil, contenidos en una pequeña urna, fueron ubicados en una recámara ubicada debajo del monumento. Sobre la urna se dispuso un "toki" de madera (artefacto asociado a los jefes indígenas) como parte del acompañamiento ritual. Otras actividades, como danzas nativas, rogativas y discursos pronunciados por descendientes del cacique, el gobernador provincial y el intendente municipal fueron realizadas para finalizar con la ceremonia (Figura 3). 
Diferentes circunstancias y hechos ocurridos como reacción ante la realización del re-entierro de Yancamil remarcan la dimensión política del mismo así como reflejan el impacto que esta ceremonia tuvo en un contexto regional y nacional. En primer término, se destaca la selección del espacio en el cual depositar los restos del cacique Rankülche. La plaza central de la ciudad de Victorica se denomina "Plaza Héroes de Cochicó”, en referencia a los soldados del ejército argentino que protagonizaron, el 19 de agosto de 1882, el denominado último combate contra los grupos indígenas de la región comandados por Yancamil en cercanías del Paraje Cochicó. Como parte de los homenajes a los soldados muertos en ese enfrentamiento se construyó en 1922 y en el medio de la plaza una pirámide conmemorativa que luego se convirtió en mausoleo, dado que contiene los restos mortales de los mismos (Figura 4). Cada 19 de agosto se efectuaba en la plaza y frente a la pirámide un acto de homenaje a los soldados del ejército y en conmemoración del éxito civilizatorio logrado en aquella batalla. De esa manera, la pirámide se convirtió a través de los años en una referencia simbólica para los ciudadanos y autoridades de Victorica y la provincia. Diferentes placas alusivas adornan los laterales del monumento, el cual puede ser visto como un recurso mnemotécnico que activa determinados procesos de memoria social y política como el de la denominada "Conquista del Desierto" o guerra contra el indio. Al respecto, para muchos ciudadanos de Victorica la pirámide a los héroes de Cochicó forma parte del recurso identitario y la batalla se constituye en "un relato que opera como una matriz de identificación y diferenciación" (Mendoza 2007: 131). Asimismo, ello explicaría las controversias y rechazos expresados por varios pobladores no Rankülches de Victorica ante el traslado de Yancamil a la plaza central, tal como ha sido registrado por Mario Mendoza: “...estamos enojados. Desde chiquito para mí los héroes son los soldados, es así... no vamos a cambiar ahora, siempre fue así. La gente no está de acuerdo en ver al indio y al soldado juntos, si lo hubieran trasladado a otro lugar, sí..." (Entrevistas realizadas a pobladores victoriquenses por Mendoza 2007: 131-132). 


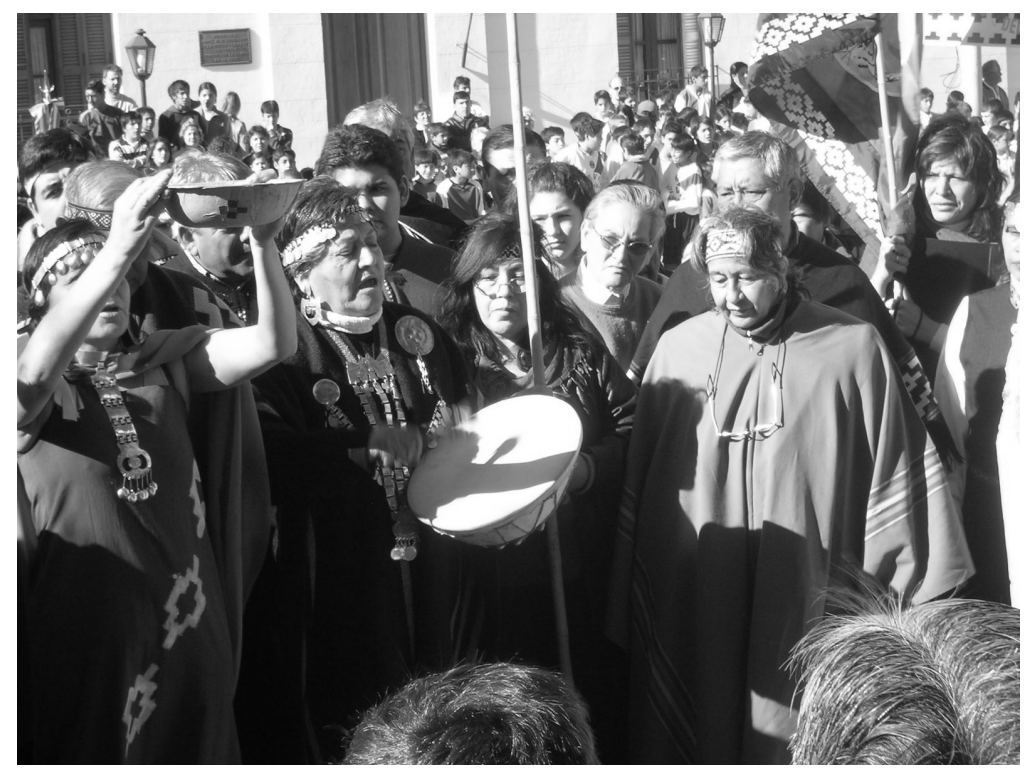

Figura 1: Miembros de la comunidad Rankülche iniciando la ceremonia de re-entierro del cacique José Gregorio Yancamil.

Figure 1: Members of the Rankülche community starting Yancamil's reburial ceremony.

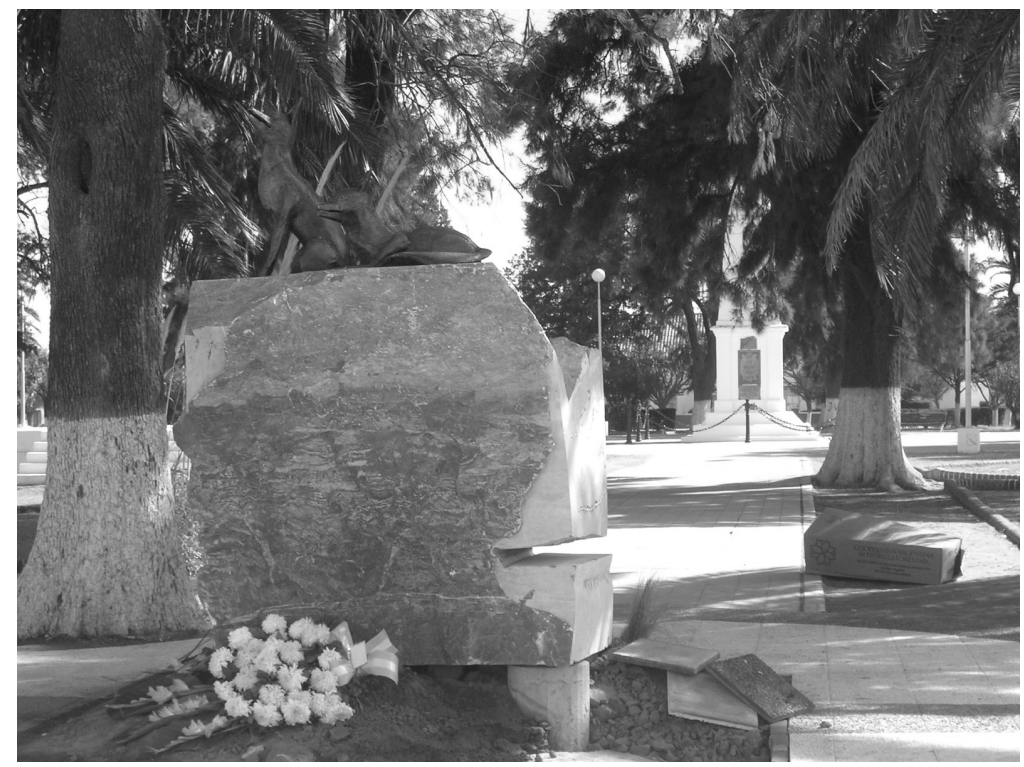

Figura 2: Vista del monumento/mausoleo a Yancamil. Al fondo se observa la pirámide a los Héroes de Cochicó. Plaza central de la ciudad de Victorica, La Pampa.

Figure 2: Panoramic view of Yancamil's monument/mausoleum. In the background view of the Cochicó Heroes's monument. Central square, city of Victorica, La Pampa. 
También se suman a estas apreciaciones las percepciones sobre los indígenas como "atrasados" y "vagos" en contraposición con las ideas de civilización y progreso aportadas por los blancos/criollos: "si fuera por ellos (e.g. indígenas) estaríamos como antes" (Ídem anterior). La evocación de la "Conquista del Desierto" y la gesta colonizadora promovida a partir de las primeras fundaciones de pueblos conforman parte de la retórica constante que fortalece y sustenta la antinomia decimonónica de civilización o barbarie. Estas significaciones históricas, consensuadas y construidas por medio de relaciones de poder y narrativas asociadas a la conformación del Estadonación y representadas en la materialidad icónica de la plaza y la pirámide, se encuentran ahora cuestionadas no tanto por la ceremonia de re-entierro sino más bien por la figura-agencia del sujeto homenajeado. No se trata de cualquier actor, sino de José Yancamil, el cacique que simboliza la lucha de resistencia indígena contra el invasor. Asimismo, no se trata de cualquier resistencia, sino de la última y precisamente apelando a esa circunstancia temporal los historiadores han cargado los diferentes relatos de la batalla con cierto aire de emotividad, nostalgia y por supuesto controversia. Al respecto, la historiografía de corte épico destaca como característica principal de la batalla de Cochicó el hecho que unos pocos soldados (25) enfrentaron y vencieron a centenares de indígenas (entre 150 a 300). De allí la asignación de héroes a los caídos y sobrevivientes de este desproporcionado enfrentamiento. Sin embargo, el mismo Yancamil, después de haber sido tomado prisionero, desacredita esa versión y relata que su grupo no era superior a los treinta lanceros munidos solamente con lanzas y boleadoras, contra un número similar de soldados con fusiles Rémington (Depetris y Cazenave 1998, Hux 2003). Quienes cuestionan la narrativa oficial invocan la circunstancia que los sargentos del ejército solían "inflar" sus reportes para potenciar ulteriores méritos y reconocimientos. Esta última alternativa no es descabellada sobre todo teniendo en cuenta que en esos momentos se comenzaban a repartir miles de hectáreas de tierras a los jefes del ejército de acuerdo a los logros obtenidos en la guerra contra el indio (Podgorny y Politis 1992). 


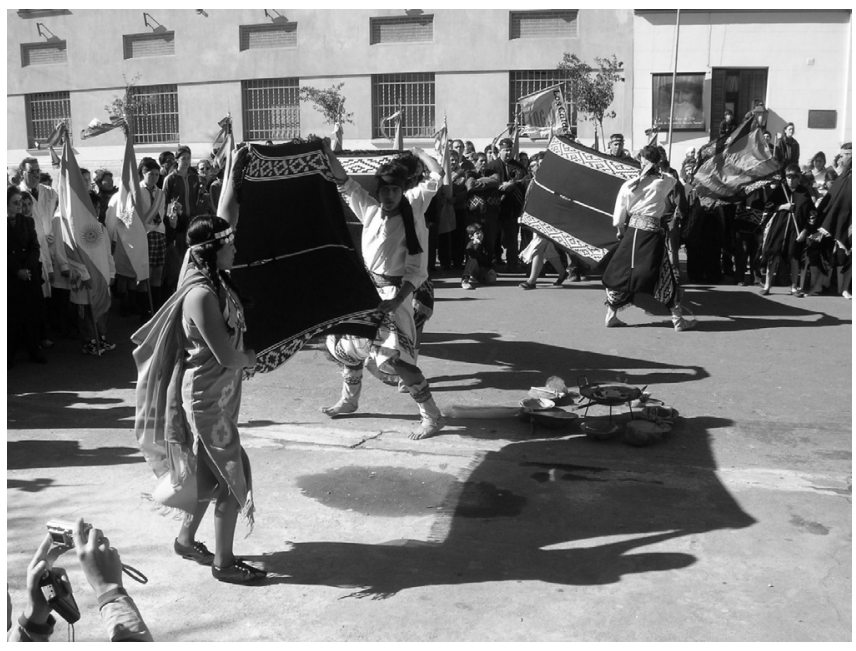

Figura 3: Danzas realizadas para conmemorar la ceremonia de re-entierro de Yancamil.

Figure 3: Dancers at the ceremony to commemorate Yancamil's reburial.

Sin dudas que la actual plaza central de Victorica, con sus monumentos y connotaciones conforma una "puesta en obra" de diferentes voces, actores, intenciones y políticas. En ese contexto, Yancamil visto como referencia onomástica simboliza "resistencia" para los indígenas, mientras que entraña "rebeldía” para el ejército, y en su acepción genérica, como "indio", remite a "vago" y "atrasado", para algunos vecinos de la ciudad. Sobre estas significaciones, se impone el discurso de las autoridades oficiales que plantea un sentido de reparación e integración, tratando de "borrar" las controversias y apelando a la construcción de una nueva identidad "pampeana" basada en la síntesis multicultural. En esta búsqueda de identidad pampeana "lo indígena" fluctúa sin anclaje bajo diferentes formas, siendo por momentos sinónimo de pasado, en el mejor de los casos de mestizaje y en otros expresado como figura patrimonializada.

\section{Oximoron Rankülche. Invisibilización visible}

La ciudad de Victorica, con su plaza, pirámide y monumento/mausoleo no están solos, unos $25 \mathrm{~km}$ al norte se encuentra la Laguna de Leubucó, antiguo asentamiento Rankülche y residencia del cacique Pangüitruz Güor (Mariano Rosas). Los pobladores de la ciudad consideran que Leubucó está en "medio de la nada" pues un amplio espacio semidesértico rodea al mismo. Sin embargo, en los últimos años un fenómeno interesante y acrecional estuvo ocurriendo en Leubucó. Casi todo lo vinculado con homenajes al 
mundo indígena fue, en diferentes momentos, “depositado" en los márgenes de la laguna (Curtoni et al. 2003, Endere y Curtoni 2066, Lazzari 2007). De esa manera, se conformó el "Parque indígena Leubucó", permeado por un sentido de reivindicación, homenaje y promoción turística, en el cual pueden observarse, como fuera mencionado antes, diferentes monumentos construidos con diversas intenciones, significaciones y valoraciones.

Estos continuos hechos de aislamiento de lo indígena en "medio de la nada" y en la periferia de la ciudad (ahora podríamos agregar también en el centro), son consecuencia de dos procesos simultáneos que denominamos de "invisibilización específica" y de "visibilización genérica". Por el primero, referimos a las estrategias de ocultamiento, silencios y negación operados sobre los sujetos, sobre el "ser" indígena, sobre las necesidades concretas de las comunidades, sobre los derechos y reclamos, sobre el activismo político y sus representantes. Como ejemplo de ello, se encuentran diferentes narrativas históricas que se han encargado de enunciar tanto la ausencia de "indios" en la provincia, como de cuestionar la legitimidad de las actuales identidades indígenas (ver discusiones en Depetris 1998, Navarro Floria 1999, Lazzari 2007). Algunas de esas narrativas oficiales fueron contestadas por voces Rankülches, como la de Germán Canuhé (lonko de la comunidad indígena Willy Kalkin), al expresar que "los escritos contemporáneos, influidos por la prédica roquista (de Julio A. Roca) de que conquistaron un desierto, ignoran la presencia de habitantes originarios en el centro de Argentina, adjudicándonos diversos orígenes, menos el único y verdadero: 'siempre estuvimos aquî'...” (Canuhé 2003).

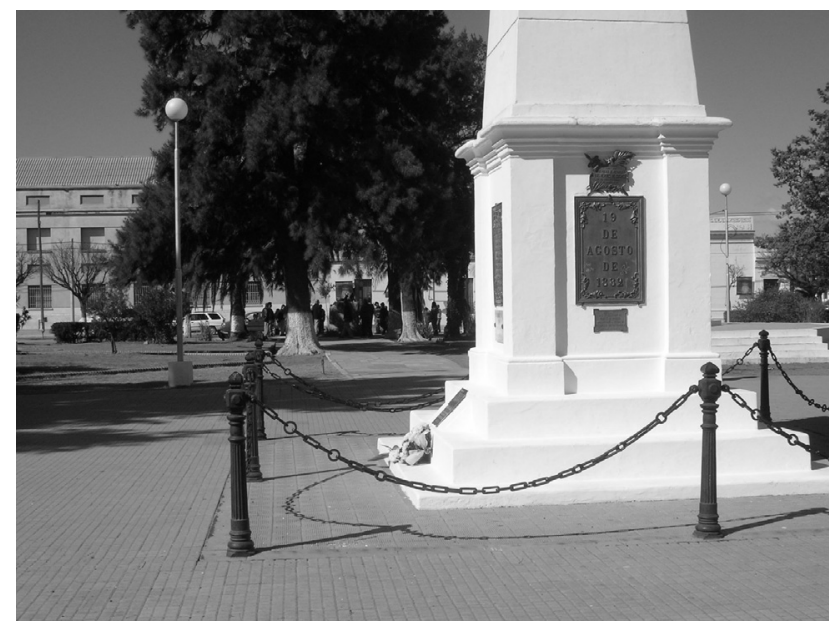

Figura 4: Vista de la Pirámide Héroes de Cochicó. Al fondo monumento a Yancamil. Figure 4: Panoramic view of the Piramide Héroes de Cochico. In the background view of the Yancamil's monument. 
En paralelo, se generan los mecanismos de visibilización genérica, puestos en escena, en general, por el poder estatal y vinculado con acciones de reparación, rescate y revalorización de "lo indígena". Las formas preferidas de expresión de este proceso son la materialización y monumentalización de "algo" referido al mundo indígena, sin mediar discusión y consenso sobre qué y cómo, con la intención de visibilizar las acciones y demostrar conciencia política. Algunas consecuencias de este mecanismo se relacionan con las inexorables tendencias de cosificación, esencialización, musealización y patrimonialización. El Parque indígena Leubucó, el monumento/ mausoleo a Yancamil, así como otros monumentos, marcas y referencias realizadas en la provincia, reflejan esta tendencia de visibilización "muda" y en algunos casos tergiversada (Curtoni 2004, Endere y Curtoni 2007, Mendoza 2007). Sin lugar a dudas, los dos procesos, engendrados en relaciones de poder, se interrelacionan, se alternan en forma compleja sin tiempo ni espacios y aunque parecen autónomos reflejan cierta dependencia mutua sin llegar a ser excluyentes. Es decir, pareciera que los dos procesos funden sus sentidos dado que la misma pre-figuración de la pretensión de invisibilidad conlleva, como resultado no deseado, su implicancia contrapuesta y, en simultáneo, las formas expresas elegidas de visibilización (al menos en el caso aquí presentado) comportan en sí mismas ocultamientos "otros". Este entrecruzamiento ambiguo de las implicaciones de los procesos de invisibilización y visibilización alimenta el sentido de omnipresencia de "lo indígena" y a su vez ello podría vincularse con el concepto de "fantasma" propuesto por Lazzari para analizar la re-emergencia étnica de los Rankülches (Lazzari 2007). Por medio de ese concepto se remite a una especie de alternativa que permite a los sujetos moverse y actuar estratégicamente entre el "dispositivo de desvanecimiento" del Ranquel, iniciado a fines del siglo XIX, y el "dispositivo de retorno" de lo Rankülche activado en las últimas décadas (Lazzari 2007).

\section{DisCUSIÓN Y COMENTARIOS FINALES}

La monumentalización del re-entierro de Yancamil pareciera desafiar, en un sentido ontológico y proxémico, no sólo al proceso histórico que trató de exterminarlos (e.g. "Conquista del Desierto") y a una forma de vida asociada con el mismo, sino también al icono (e.g. pirámide de Cochicó) y a los agentes representados. Ahora, una parte de lo indígena se encuentra en el corazón de la ciudad enfrentando la pirámide, si bien bajo una forma "congelada", "muda", "patrimonializada", conforma una especie de "práctica intersticial de libertad" (sensu Lazzari 2007: 92), que posibili- 
ta resignificar las acciones de reconocimiento provincial y connotar en su materialidad, al menos, la existencia de "algo de lo indígena". El monumento/mausoleo, como recurso mnemotécnico, tiene el potencial de poder activar memorias y valoraciones, que pueden ser heterogéneas, tanto entre los descendientes indígenas como entre los no indígenas. Esto remarca el hecho que un mismo referente (en este caso el monumento) puede constituirse en diferentes patrimonios dependiendo de quién lo está percibiendo y qué procesos de memoria se connotan, activan y construyen en cada uno. La potencial pluriversalidad que puede detonar el monumento/mausoleo a Yancamil ha quedado expresada en las diferentes visiones y versiones que el mismo refiere para algunos representantes de las comunidades indígenas, el ejército, las autoridades, los ciudadanos no indígenas de Victorica y los "académicos".

En síntesis, el monumento en sí mismo puede ser visto como actuando en la ambigüedad, otorga visibilización al tiempo que invisibiliza, dice y no dice. En ese sentido, se constituye en un efectivo 'dispositivo de poder' (sensu Foucault 1997), pues invisibiliza (en forma específica) cosificando el "ser" y "estar" indígena, congela una dinámica transtemporal, opera enmudeciendo voces, no dice de la cosmovisión, percepción, creencias, leyendas, reclamos, etc. Asimismo, el monumento visibiliza (en general) refiriendo como mínimo a "algo" de lo indígena, aunque ese algo pueda provocar diferentes reacciones y estar asociado con los homenajes, las memorias, las reparaciones y los pasados. Esas posibilidades conforman "lo dicho" por medio de la materialización y en ocasiones lo dicho (como hegemónico) reserva el indulgente lugar de la inexistencia contemporánea de indígenas. Pero también el monumento, como "memoria de piedra” puede simbolizar estrategias contra-hegemónicas del activismo indígena (lo no dicho), posibilitando promover lugares "otros" y/o intersticios desde los cuales operar en función de intereses propios, aun con elementos aportados por el aparato oficial.

Por otro lado, si bien en los últimos años las políticas de "reconocimiento" y "reparación" del gobierno provincial pueden considerarse como activas (aunque asociadas a los sentidos de colonialidad moderna), las mismas no han dado cuenta de los reclamos de tierras y de los actuales problemas de despojo que sufren campesinos e indígenas de los lugares que tradicionalmente ocupan (Curtoni et al. 2007). Estas políticas contemporáneas, al desatender y/o negar los derechos que legalmente corresponden a los pueblos indígenas y que forman parte de los reclamos cotidianos, también invisibilizan de manera específica. Como lo expresa Ana María Do- 
mínguez (descendiente Rankülche) en relación a la falta de correspondencia ante los pedidos concretos: "A nosotros no nos queda lugar ni para enterrar a los muertos. Nosotros reclamamos lugares sagrados que pertenecen a los pueblos indígenas. Para nosotros, todos los lugares donde hubo población indígena hay una presencia sagrada. Sagrado es todo, todo es espiritualidad para nosotros porque somos parte de la naturaleza. Cada comunidad tiene sus reclamos puntuales por espacios territoriales propios para realizar sus ceremonias" (ver Endere y Curtoni 2006).

En 1994, el texto reformado de la Constitución de la Nación Argentina incorporó el siguiente inciso 17 al artículo 75: "Corresponde al Congreso reconocer la preexistencia étnica y cultural de los pueblos indígenas argentinos. Garantizar el respeto a su identidad; [...] reconocer la personería jurídica de sus comunidades y la posesión y propiedad comunitarias de las tierras que tradicionalmente ocupan; y regular la entrega de otras aptas y suficientes para el desarrollo humano; [...] Asegurar su participación en la gestión referida a sus recursos naturales" (Constitución de la Nación Argentina, 1994). Sin embargo, en la provincia de La Pampa, como en muchas otras provincias de Argentina (Dargoltz 2003, Ferrara 2007, Curtoni y Chaparro 2007), el artículo constitucional no dejó de ser una instancia meramente declarativa, letra muerta sin aplicación concreta. Esta es una de las tantas acciones "paradójicas" del estado provincial, que por un lado reconoce y realiza homenajes a los indígenas y en simultáneo, oculta y silencia los reclamos concretos y puntuales. Sin dudas, estos hechos en apariencia contradictorios y ambivalentes no hacen otra cosa que demostrar el amplio horizonte y capacidad/poder de acción, efectos y reacción promovidos por el mismo agente.

Por último, como mencionamos anteriormente, el re-entierro del cacique José Gregorio Yancamil generó distintas sensaciones y reacciones, acuerdos y desacuerdos. Al parecer, la decisión para trasladar los restos de Yancamil a la plaza central estuvo mediada por el expreso consentimiento y acuerdo del pueblo Rankülche, tal como lo expresa Luis Dentoni Yancamil, bisnieto del cacique "...en el 2005 hicimos una reunión de comunidades para acordar, y si el pueblo rankel no estaba de acuerdo no se hacía... por suerte estuvieron todos de acuerdo" (Dentoni com. pers. 2006 [entrevista personal]). Por el contrario, la iniciativa fue cuestionada por el escritor y periodista Osvaldo Bayer, en nombre de la Asociación Awka Liwen, considerando que era inadmisible ubicar a Yancamil en un espacio donde "se glorifica a las fuerzas que actuaron en la violenta represión contra los indígenas. Yancamil no hubiera aceptado ser recordado y homenajeado en una ciudad 
y en una plaza donde se inmortaliza precisamente a los que sirvieron a esa guerra injusta de exterminio..." (Diario La Arena 19-08-2006). Estas controversias, sumadas a las opiniones de algunos vecinos de Victorica (Mendoza 2007), expresan que el proyecto de re-entierro del cacique debió haber tenido instancias más abarcadoras de conversación, discusión y consenso con los distintos actores interesados, tanto para poner en consideración el tema del re-entierro en sí mismo como también la forma de plasmar un posible homenaje.

Más allá de la presencia monolítica de Yancamil en la "Plaza Héroes de Cochicó", se puede sostener que algo ha cambiado últimamente. Ese espacio se convierte en una oportunidad para que se pongan en juego y activen diferentes mecanismos donde confluyen las contradicciones, tensiones y conflictos, revitalizando y resignificando las historias locales y donde los protagonistas pueden ser, en cualquier momento, actores diversos con intenciones y valoraciones distintas. No hay dudas que la ceremonia de re-entierro de Yancamil con su memorial de piedra, presentado aquí como caso de análisis, es un hecho consumado que en su propia finalización inaugura la puesta en marcha de un entramado dinámico y heterogéneo de significaciones y resignificaciones, continuas, discontinuas, desafiantes, condescendientes, etc. Asimismo, el reconocimiento de espacios de conflicto y tensión, de pluriversalidades, de lo "no dicho", de los intersticios y estrategias, no hacen otra cosa que desnudar, al tiempo que reclamar, la puesta en juego de voces y saberes "otros" generados en la diferencia y/o subalternizados. Como los ya mencionados relatos de los propios indígenas acerca del origen del pueblo Rankülche (e.g. Canuhé 2003), las connotaciones de lugares sagrados, los reclamos territoriales y las opiniones divergentes sobre el re-entierro de Yancamil vinculadas con la alteración del descanso del jefe indígena.

De esta manera, el espacio de oportunidad se conforma en una especie de palimpsesto de actores, significaciones, intereses y visiones que pueden entrar en pugna y alejarse o promover interrelaciones y fluidez de sentidos. En ese contexto, la perspectiva decolonial promueve, por medio del pensamiento heterárquico, la puesta en obra, discusión y resignificación de saberes e ideas generados desde la diferencia colonial y apuesta a las construcciones del conocimiento "en lugar" (Castro Gómez 2007, Dávalos 2005, Dussel 2003, Escobar 2005, Grosfoguel 2007, Mignolo 2003). Asimismo, en este giro decolonial deberíamos dar un paso más y reconocer desde nuestra propia arrogancia y limitaciones que ya existen esos "espacios otros" donde se configuran distintos saberes con otras epistemologías, cos- 
movisiones y racionalidades. Estos saberes no necesitan ser empoderados (actitud paternalista bastante común en algunos discursos postcoloniales) y mucho menos del concurso académico o del guińo "experto" para poder posicionarse y obtener credibilidad, legitimidad y existencia. Esos saberes ya "son" desde sus propias formas y lo que necesitamos es un giro que parta más que nada de la lucha de la decolonialidad, "haciendo ver de este modo la complicidad modernidad-colonialidad como marco central que sigue organizando y orientando 'las ciencias' y el pensamiento académico-intelectual" (Walsh 2007: 111). De esa forma, antes que considerarlas como una opción teórica, las perspectivas de la decolonialidad parecen abrirse paso como alternativas éticas y políticas. Invisibilización visible, omnipresencia indígena, "fantasma", palimpsesto, el oxímoron Rankülche expresa "siempre estuvimos aquî" y exuda resistencia. Los resultados de esta oportunidad/alternativa son difíciles de prever, pero sin dudas todo este proceso ha servido para poner en obra una escena olvidada con actores también olvidados que esperaban saltar a la palestra.

Agradecimientos: Los trabajos realizados en la provincia de La Pampa forman parte del Núcleo de Investigación INCUAPA (Investigaciones Arqueológicas del Cuaternario Pampeano), dirigido por el Dr. Gustavo Politis y financiado por la Agencia Nacional de Promoción Científica y Tecnológica (ANPCyT). Agradecemos a Andrés Troncoso por la invitación a participar en este volumen.

\section{BiBLIOGRAFÍA}

Achugar, H. 2003."El lugar de la memoria, a propósito de monumentos (Motivos y paréntesis)". En Monumentos, Memoriales y Marcas Territoriales, editado por E. Jelin y V. Langland, pp: 191-216. Siglo XXI de Espańa Editores, Madrid.

Arizpe, L. 2000. "Cultural Heritage and Globalisation”. En Values and Heritage Conservation. Research Report, editado por E. Avrami, R. Mason y M. de la Torre, pp: 32-37. The Getty Conservation Institute, Los Angeles.

Avrami, E.; R. Mason y M. de la Torre. 2000. Values and Heritage Conservation. Research Report. The Getty Conservation Institute, Los Angeles.

Ayala, P. 2005."Pueblos originarios y arqueología: discursos en torno al patrimonio arqueológico en San Pedro de Atacama (Segunda Región, Chile)”. Textos Antropológicos 15 (2): 249-261.

Bender, B. 1998.Stonehenge. Making Space. Berg, Oxford. 
Bertoni, L. 1992."Construir la Nacionalidad: Héroes, estatuas y fiestas patrias, 1887-1891”. Boletín del Instituto de Historia Argentina y Americana Dr. E. Ravignani, Tercera serie, 5: 77-111.

Byrne, D. 1991."Western Hegemony in Archaeological Heritage Management”. History and Anthropology 5: 269-276.

Canuhé, G. 2003. Reseña histórica de la Nación Mamülche, Pueblo Rankül (ranquel), habitante desde siempre del centro de la actual Argentina. Manuscrito.

Carman, J.; M. Cooper, A. Firth y D. Wheatley. 1995."Conclusion. Opening a debate”. En Managing Archaeology, editado por M. Cooper, A. Firth, J. Carman y D. Wheatley, pp: 235-241. Routledge, Londres.

Castiblanco Roldán, A. 2007."El lugar de memoria como espacio patrimonial y de representación: la Plaza de los Mártires y los Edificios de sus alrededores en Bogotá". En Las vías del patrimonio, la memoria y la arqueología, editado por D. Patińo C., pp: 81-106. Editorial de la Universidad del Cauca, Colombia.

Castro Gómez, S. 2003. "Ciencias Sociales, violencia epistémica y el problema de la invención del otro". En La colonialidad del saber: eurocentrismo y ciencias sociales. Perspectivas latinoamericanas, editado por E. Lander, pp: 145-161. CLACSO, Buenos Aires.

Castro Gómez, S. 2007. "Decolonizar la universidad. La hybris del punto cero y el diálogo de saberes". En El giro decolonial. Reflexiones para una diversidad epistémica más allá del capitalismo global, editado por S. Castro Gómez y R. Grosfoguel, pp: 79-91. Siglo del Hombre Editores, Universidad Central, Instituto de Estudios Sociales Contemporáneos y Pontificia Universidad Javeriana, Instituto Pensar, Bogotá.

Cleere, H. 1996."The concept of "outstanding universal value" in the World Heritage Convention". Conservation and Management of Archaeological Sites 1: 227-233.

Coronil, F. 2003. "Naturaleza del poscolonialismo: del eurocentrismo al globocentrismo". En La colonialidad del saber: eurocentrismo y ciencias sociales. Perspectivas latinoamericanas, editado por E. Lander, pp: 87-111. CLACSO, Buenos Aires.

Curtoni, R. 2004. "La dimensión política de la arqueología: el patrimonio indígena y la construcción del pasado". En Aproximaciones contemporáneas a la Arqueología pampeana. Perspectivas teóricas, metodológicas, analiticas y casos de estudio, editado por G. Martínez, M. Gutiérrez, R. Curtoni, M. Berón y P. Madrid, pp: 437-449. Facultad de Ciencias Sociales, Olavarría. 
Curtoni, R.; A. Lazzari y M. Lazzari. 2003."Middle of nowhere: a place of war memories, commemoration and aboriginal re-emergence (La Pampa, Argentina)". World Archaeology 35 (1): 61-78.

\section{Curtoni, R.; M. G. Chaparro, R. Dargoltz, N. Véliz, N. Mendoza, C. Salomón,} M. Comerci y L.Valencia. 2007. "No hay hombres sin tierras ni tierras sin hombres. El despojo de los campesinos santiagueños y pampeanos." Actas de Resúmenes de la Reunión de Teoría Arqueológica en América del Sur. San Fernando del Valle de Catamarca.

Curtoni, R. y M. G. Chaparro. 2007."El espejo de la naturaleza y la enfermedad histórica en la construcción del conocimiento". Intersecciones en Antropología 8 , en prensa.

Dargoltz, R. 2003. Hacha y Quebracho. Historia ecológica y social de Santiago del Estero. V Edición, Marcos Vizoso Ediciones, Santiago del Estero.

Dávalos, P. 2005. "Movimientos indígenas en América Latina: el derecho a la palabra”. En Pueblos Indigenas, Estado y Democracia, compilado por P. Dávalos, pp: 17-33. CLACSO, Buenos Aires.

Depetris, J. C. 1998. "Los indígenas de la Pampa Central. Segundo Censo Nacional de Población de 1895”. En Memorias de las Jornadas Ranquelinas, editado por M. Poduje, pp: 133-147. Departamento de Investigaciones Culturales, Instituto Nacional de Asuntos Indígenas, Santa Rosa, La Pampa.

Depetris, J. C. y W. Cazenave. 1998.Crónicas Ranquelinas. Departamento de Investigaciones Culturales, Instituto Nacional de Asuntos Indígenas, Santa Rosa, La Pampa.

Diario La Arena. 2006. “Trasladan al cacique Yancamil a la plaza”. Nota del 19 de agosto de 2006, página 21. Santa Rosa, La Pampa.

Dussel, E. 2003. "Europa, modernidad y eurocentrismo". En La colonialidad del saber: eurocentrismo y ciencias sociales. Perspectivas latinoamericanas, editado por E. Lander, pp: 41-53. CLACSO, Buenos Aires.

Endere, M. L. 2002. "The reburial issue in Argentina: a growing conflict”. En The Dead and their Possessions. Repatriation in principle, policy and practice, editado por C. Fforde, J. Hubert y P. Turnbull, pp: 266-283. Routledge, Londres.

Endere, M. L. 2005.” Discusión del Ensayo de Opinión de Elena Belli y Ricardo Slavutsky "Patrimonio: Territorio, objetos, símbolos, personas. ¿Cuál es la disputa?". Mundo de Antes 4: 18-20.

Endere, M. L. 2007. Management of Archaeological Sites and the Public in Argentina. BAR, British Archaeological Research Series, Oxford. 
Endere, M. L. y R. Curtoni. 2006. “Entre lonkos y “ólogos”. La participación de la comunidad indígena Rankülche de Argentina en la investigación arqueológica”. Arqueología Suramericana 2 (1): 72-92.

Endere, M. L. y R. Curtoni. 2007."El patrimonio cultural del área centro-este de La Pampa: la conmemoración de dos pasados antagónicos”. En Arqueología en Las Pampas, editado por C. Bayón, A. Pupio, M. I. González, N. Flegenheimer y M. Freire, pp: 799-812. Sociedad Argentina de Antropología, Buenos Aires.

Escobar, A. 2005. Más allá del Tercer Mundo. Globalización y Diferencia. Instituto Colombiano de Antropología e Historia, Bogotá.

Ferrara, F. 2007.Los de la tierra. De las ligas agrarias a los movimientos campesinos. Tinta Limón Ediciones, Buenos Aires.

Foucault, M. 1997.La arqueología del saber. Siglo XXI Editores, México.

Gnecco, C. 2003."El erotismo de la desnudez arqueológica”. En Arqueología al desnudo. Reflexiones sobre la práctica disciplinaria, editado por C. Gnecco y E. Piazzini, pp: 5-24. Editorial Universidad del Cauca, Popayán, Colombia.

Gnecco, C. 2005. “Ampliación del campo de batalla. Simposio Pueblos Originarios y Arqueología (Memorias)”. Textos Antropológicos 15(2): 183-195.

Grosfoguel, R. 2007. "Implicaciones de las alteridades epistémicas en la redefinición del capitalismo global: transmodernidad, pensamiento fronterizo y colonialidad global”. En ¿Uno solo o varios mundos? Diferencia, subjetividady conocimientos en las ciencias sociales contemporáneas, editado por M. Zuleta, H. Cubides y M. Escobar, pp: 99-116. Siglo del Hombre Editores; Universidad Central, Instituto de Estudios Sociales Contemporáneos, Bogotá.

Haber, A. 2004. "Arqueología de la naturaleza/naturaleza de la arqueología”. En Hacia una arqueología de las arqueologías sudamericanas, editado por A. Haber, pp: 15-31. Centro de Estudios Socioculturales e Internacionales, Facultad de Ciencias Sociales, Universidad de los Andes, Bogotá.

Hewison, R., 1987. The Heritage Industry. Methuen, Londres.

Holtorf, C. 2001. "Is the past a non-renewable resource?". En Destruction and Conservation of Cultural Property, editado por R. Layton, P. Stone y J. Thomas, pp: 286-297. Routledge, Londres.

Hux, M. 2003. Caciques Pampa-Ranqueles. Ediciones El Elefante Blanco, Buenos Aires.

Jauretche, A. [1957] 2004.Los profetas del odio y la yapa. Editorial Peña Lillo, Buenos Aires. 
Jelin, E. y V. Langland. 2003.Monumentos, memoriales y marcas territoriales. Siglo XXI Editores, España y Argentina.

Lander, E. 2003. “Ciencias sociales: saberes coloniales y eurocéntricos”. En La colonialidad del saber: eurocentrismo y ciencias sociales. Perspectivas latinoamericanas, editado por E. Lander, pp: 11-40. CLACSO, Buenos Aires.

Langebaek, C. 2005. “Arqueología colombiana: balances y retos”. Arqueología Suramericana Vol. 1 (1): 96-114.

Langford, R. 1983. "Our Heritage - Your playground”. Australian Archaeology, 16: 1-6.

Larsen, K. 1995.Nara Conference on Authenticity. Nara, Japan, 1-6 November, 1994. Proceeding. UNESCO World Heritage Centre, Agency for Cultural Affairs (Japan), ICCROM, ICOMOS. Agency for Cultural Affairs, Tokio.

Layton, R. 1989. Who needs the Past? Indigenous values and archaeology. Routledge, Londres.

Lazzari, A. 2007. "Identidad y fantasma: situando las nuevas prácticas de libertad del movimiento indígena en La Pampa". Quinto Sol Revista de Historia Regional, 11: 91-122.

Le Goff, J. 1991. El orden de la memoria: el tiempo como imaginario. Paidós, Barcelona.

Mamani Condori, C. 1989."History and Prehistory in Bolivia: what about the Indians?”. En Conflict in the archaeology of living traditions, editado por R. Layton, pp: 46-59. Unwin Hyman, Londres.

Maldonado Torres, N. 2007. "Sobre la colonialidad del ser: contribuciones al desarrollo de un concepto”. En El giro decolonial. Reflexiones para una diversidad epistémica más allá del capitalismo global, editado por S. Castro Gómez y R. Grosfoguel, pp: 127-167. Siglo del Hombre Editores, Universidad Central, Instituto de Estudios Sociales Contemporáneos y Pontificia Universidad Javeriana, Instituto Pensar, Bogotá.

Mendoza, M. 2007. "Identidad y políticas de reconocimiento: discurso y prácticas en la construccción de la alteridad de los pueblos originarios”. Quinto Sol Revista de Historia Regional, 11: 123-142.

Merriman, N. 1991.Beyond the Glass Case. The Past, the Heritage and the Public. Leicester University Press, Leicester.

Mignolo, W. 2003. Historias locales / diseños globales: colonialidad, conocimientos subalternos y pensamiento fronterizo. Editorial Akal, Madrid. 
Mignolo, W. 2007.“El pensamiento decolonial: desprendimiento y apertura. Un manifiesto". En El giro decolonial. Reflexiones para una diversidad epistémica más allá del capitalismo global, editado por S. Castro Gómez y R. Grosfoguel, pp: 25-46. Siglo del Hombre Editores, Universidad Central, Instituto de Estudios Sociales Contemporáneos y Pontificia Universidad Javeriana, Instituto Pensar, Bogotá.

McNiven, I. y L. Russell. 2005. Appropriated Pasts. Indigenous Peoples and the Colonial Culture of Archaeology. Altamira Press, Oxford.

Navarro Floria, P. 1999. "Un país sin indios. La imagen de La Pampa y la Patagonia en la geografía del naciente Estado argentino”. Scripta Nova. Revista electrónica de Geografía y Ciencias Sociales Nro. 51. Universidad de Barcelona, Barcelona.

Piazzini, C. 2006. "De las artes de la memoria a la geopolítica de la memoria”. En Escenarios de Reflexión. Las ciencias Sociales y Humanas a debate, compilado por O. García y M. Ruiz García, pp. 115-134. Universidad Nacional de Colombia, Medellín.

Podgorny. I. y G. Politis. 1992. ¿QQue sucedió en la historia? Los esqueletos araucanos del Museo de La Plata y la Conquista del Desierto”. Arqueología contemporánea, 3: 73-79.

Politis, G. y J. Pérez Gollán 2004. "Latin American Archaeology: from colonialism to globalization”. En A Companion to Social Archaeology, editado por L. Meskell y R. Preucel, pp: 353-373. Blackwell, Londres.

Pressouyre, L. 1996. The World Heritage Convention 20 years later. UNESCO Publishing, París.

Preucel, R. y I. Hodder. 1996. "Constructing Identities”. En Contemporary Archaeology in Theory. A Reader, editado por R. Preucel y I. Hodder, pp: 601614. Blackwell, Oxford.

Quijano, A. 2003. "Colonialidad del poder, eurocentrismo y América Latina”. En La colonialidad del saber: eurocentrismo y ciencias sociales. Perspectivas latinoamericanas, editado por E. Lander, pp: 201-246. CLACSO, Buenos Aires.

Restrepo, E. 2007. "Antropología y colonialidad". En El giro decolonial. Reflexiones para una diversidad epistémica más allá del capitalismo global, editado por S. Castro Gómez y R. Grosfoguel, pp: 289-304. Siglo del Hombre Editores, Universidad Central, Instituto de Estudios Sociales Contemporáneos y Pontificia Universidad Javeriana, Instituto Pensar, Bogotá.

Santos, B. de S. 2006. Renovar la teoría crítica y reinventar la emancipación social: encuentros en Buenos Aires. CLACSO, Buenos Aires. 
Shanks, M. y C. Tilley. 1987. Social theory and Archaeology. University of New Mexico Press, Albuquerque.

Tilley, C. 1989. "Archaeology as socio-political action in the present". En Critical Traditions in Contemporary Archaeology, editado por V. Pinsky y A. Wylie, pp: 104-116. University of New Mexico Press, Albuquerque.

Trigger, B. 1981. "Anglo-American archaeology". World Archaeology, 13: 138155.

Trigger, B. 1984 (1996). “Alternative Archaeologies: nationalist, colonialist, imperialist". En Contemporary Archaeology in Theory. A Reader, editado por R. Preucer y I. Hodder, pp: 615-631. Blackwell, Oxford.

Ucko, P. 2000. “Enlivening a 'dead' past”. Conservation and Management of Archaeological Sites, 4 (2): 67-92.

Ucko, P. 2001."Heritage and indigenous Peoples in the 21st century". Public Archaeology, 1: 227-238.

UNESCO. 2000.El Patrimonio Mundial. Editorial de la Unesco, París.

Verdesio, G. 2005."La mudable suerte del amerindio en el imaginario uruguayo: su lugar en las narrativas de la nación de los siglos XIX y XX y su relación con los saberes expertos". En Hacia una Arqueología de las Arqueologías Sudamericanas, editado por A. Haber, pp. 115-150. Ediciones Uniandes, Bogotá.

Walsh, C. 2007. ¿¿Son posibles unas ciencias sociales/culturales otras? Reflexiones en torno a las epistemologías decoloniales". Nómadas 26: 102-113.

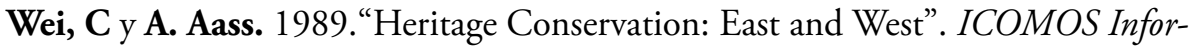
mation, 3: 3-8. 